\title{
Molecular analysis of a fragment of gene E1B 19K of canine adenovirus 2 (CAV-2) isolated from dogs with symptoms of cough
}

\author{
M. Kalinowski ${ }^{1}$, Ł. Adaszek ${ }^{1}$, P. Miłoszowska ${ }^{1}$, M. Skrzypczak ${ }^{2}$, \\ A. Ziętek-Barszcz ${ }^{3}$, J. Kutrzuba' ${ }^{1}$ Z. Grądzki ${ }^{1}$, S. Winiarczyk ${ }^{1}$ \\ ${ }^{1}$ Department of Epizootiology and Infectious Diseases, Faculty of Veterinary Medicine, \\ University of Life Sciences Lublin, Głęboka 30, 20-612 Lublin, Poland \\ ${ }^{2}$ Second Department of Gynecology, Prof. F. Skubiszewski University School of Medicine, \\ Jaczewskiego 8, 20-090 Lublin, Poland \\ ${ }^{3}$ Department of Epidemiology and Risk Assessment, The National Veterinary Research Institute, \\ Partyzantów Avenue 57, 24-100 Puławy.
}

\begin{abstract}
The aim of this study was to perform molecular analysis of canine adenovirus 2 (CAV-2) E1B $19 \mathrm{~K}$ gene fragment isolated from 20 dogs of various breeds (12 males and 8 females aged 1-9 years), with clinical symptoms of upper respiratory tract infections, from the Lubelszczyzna region. Nasal swabs were taken from dogs. DNA of CAV-2 was detected using the PCR method in 16 swabs. All PCR products were sequenced, and the obtained sequences were compared with each other and with the sequence of the E1B 19K gene of the CAV-2 strain from an online database of NCBI GenBank: $\mathrm{AC}$ 000003. Based on analysis of the obtained sequences, three polymorphic variants of CAV-2 (No.1-3) with homology of $78-100 \%$ were distinguished. The nucleotide and amino acid sequences of the most frequently represented polymorphic variant, No. 1, differed from the sequences of polymorphic variant No. 2 with one substitution. The nucleotide and amino acid sequence of the E1B 19K gene of CAV-2 AC 000003 differed from the analogous sequences of representatives of variant No. 1 with 44 nucleotide and 19 amino acid substitutions. The small number of nucleotide differences in the E1B 19K CAV-2 gene among the examined own isolates, compared with AC 000003, suggest that the infections in dogs were caused by a relatively genetically stable virus which occurs in eastern Poland.
\end{abstract}

Key words: CAV-2, dogs, PCR, sequencing 


\section{Introduction}

Adenoviruses are pathogens isolated from humans, as well as farm and domestic animals (Wieliczko et al. 2003, Wiśniewski 2004, Koncicki et al. 2006, Buonavoglia and Martella 2007, Lynch et al. 2011, Truszczyński and Pejsak 2012). Canine adenoviruses (CAVs) belong to the Adenoviridae family, the Mastadenovirus genus. They are non-enveloped viruses sized 70-90 nm, whose genome, in the form of a double DNA strand, is built of 36-44 kilobase pairs. Their capsid is assembled from 252 capsomeres and the top capsomeres have a single, thread-like projection (Appel and Binn 1987). Currently, two antigen types of adenoviruses isolated from dogs are recognised: CAV-1, inducing infectious canine hepatitis (Rubarth's disease), and CAV-2, an aetiological factor of canine tracheobronchitis (kennel cough) (Chaturved et al. 2008). CAV-2 demonstrates an affinity to the epithelia of upper airways, mostly of the nose, throat, larynx and trachea (Appel et al. 1970). It can also contribute to intestinal inflammations (Hamelin et al. 1985, Macartney et al. 1988). Its presence was revealed in the brain of dogs exhibiting neurological symptoms (Benetka et al. 2006). The virus was isolated for the first time in 1961 in Canada from dogs with symptoms of laryngitis and tracheitis (Ditchfield et al. 1962). The discovered strain was named Toronto A26/61 and it was initially regarded as a variety of CAV-1. However, further studies showed structural and antigen differences between these viral isolates and as a result Toronto A26/61 was recognised as a separate strain and named CAV-2 (Yamamoto and Marusyk 1968, Fairchild and Cohen 1969, Swango et al. 1969, Marusyk et al. 1970, Marusyk 1972, Hamelin et al. 1984). The total analysis of the genome of these adenoviruses showed their homology only in $75 \%$ (Morrison et al. 1997, Davison et al. 2003).

The CAV-2 genome contains genes encoding numerous proteins that have specific functions during infection of the host's cells. The most important ones are: E1A and E1B (19K and 55K), E3, E4, pIVa2, pIIIa, pVI, pVII, pVIII, Pol, pTP, DBP. Of the listed genes, E1B $19 \mathrm{~K}$ is frequently used to detect CAV-2 in biological material. It expresses a protein of the same name that is responsible for inhibition of apoptosis of the host cells (White et al. 1988).

Because no studies on the incidence of CAV-2 infections in dogs in Poland have been conducted so far, and no molecular monitoring of CAV-2 isolated from clinical cases of kennel cough has been carried out in Poland, the aim of this paper was to conduct a molecular analysis of gene E1B $19 \mathrm{~K}$ of the CAV-2 isolated from clinical cases of infectious tracheobronchitis in dogs.

\section{Materials and Methods}

\section{Animals used in the study and sample collection}

The study covered 20 dogs of various breeds (12 males and 8 females aged 1-9, marked with numbers from 001 to 020), patients of the Clinic of Infectious Diseases in Lublin, with suspected CAV-2 infection. The animals came from the Lubelskie Region and exhibited symptoms of upper airway infection (nasal discharge and cough). All the specimens had been vaccinated against distemper, canine parvovirosis, Rubarth's disease, infections with type 2 adenovirus and parainfluenza over the period of the previous six months. The animals were tested for distemper (negative) and CAV-2 infections. Nasal smears collected using sterile swabs which were later soaked with Eagle's medium with antibiotics (penicillin, streptomycin) were used as material for virological tests. The material was shaken and then moved to eppendorf test tubes.

\section{DNA extraction and amplification}

The genetic material of CAV-2 was isolated using a Genomic mini DNA isolation kit (A\&A Biotechnology, Gdańsk, Poland) according to the procedure provided by the manufacturer. Purified DNA was suspended in $100 \mu \mathrm{l}$ of Tris buffer to be used in further analysis.

The amplification of E1B-19K CAV-2 gene was performed using the forward primer CAV-F 5'-GAGCAGGTAGTATGGAC-3; CAV-R 5'-TCAGTAAAAGRAGCAAC-3'. The primers made it possible to amplify a gene fragment of 235 base pairs (Gerhold et al. 2007).

The $50 \mu$ PCR reaction mixture consisted of: 33 $\mu \mathrm{l}$ of water, $5 \mu \mathrm{l}$ of buffer for Taq polymerase, $1 \mu \mathrm{l}$ of dNTP $(10 \mathrm{mM}), 3 \mu \mathrm{l}$ of $\mathrm{MgCl} 2(25 \mathrm{mM}), 1 \mu \mathrm{l}$ of each primer: CAV-F and CAV-R with a concentration of $50 \mathrm{pM}, 1 \mu \mathrm{l}$ of Taq DNA Polymerase $5 \mathrm{u} / \mu \mathrm{l}$ (Fermentas) and $5 \mu \mathrm{l}$ of matrix (DNA isolated earlier). The PCR was conducted using Biometra apparatus (Gottingen, Germany). It covered 40 cycles, each consisting of a stage of DNA denaturation at $94^{\circ} \mathrm{C}$ for one minute, annealing of primers at $50^{\circ} \mathrm{C}$ for 1 minute and strand extension at $72^{\circ} \mathrm{C}$ for 1 minute. The reaction was conducted using positive and negative control. CAV genetic material isolated from Nobivac DHP vaccine (Intervet) was used as positive control, whereas the total DNA isolated from nasal smears collected from a healthy dog served as negative control. 


\section{Electrophoresis}

Products of the PCR were analysed using the electrophoresis method in 1.5\% agarose gel, in TBE buffer, at a voltage of $10 \mathrm{~V} / \mathrm{cm}$. The gel was stained with ethidium bromide $(1 \mu \mathrm{g} / \mathrm{ml})$ for 15 minutes. The size of products was determined according to the weight standard DNA ladder 100 bp (Fermentas).

\section{DNA sequencing}

The amplicons obtained were purified on columns using a QIAquick PCR Purification Kit (Qiagen, Hilden, Germany). The purified products were sequenced in the Laboratory of DNA Sequencing and Oligonucleotide Synthesis of the Institute of Biochemistry and Biophysics, Polish Academy of Sciences, Warsaw. The sequencing results were received via e-mail and developed using Lasergene MegAlign software (Madison, USA). The developed sequences of own isolates were then compared to one another and then to the standard sequence of the E1B-19K gene from isolate AC 000003 from the NCBI GenBank.

\section{Results}

\section{PCR}

PCR showed the presence of CAV-2 genetic material in 16 of the 20 tested nasal swabs. All the products obtained in the PCR had the expected size of 235 bp (Fig. 1).

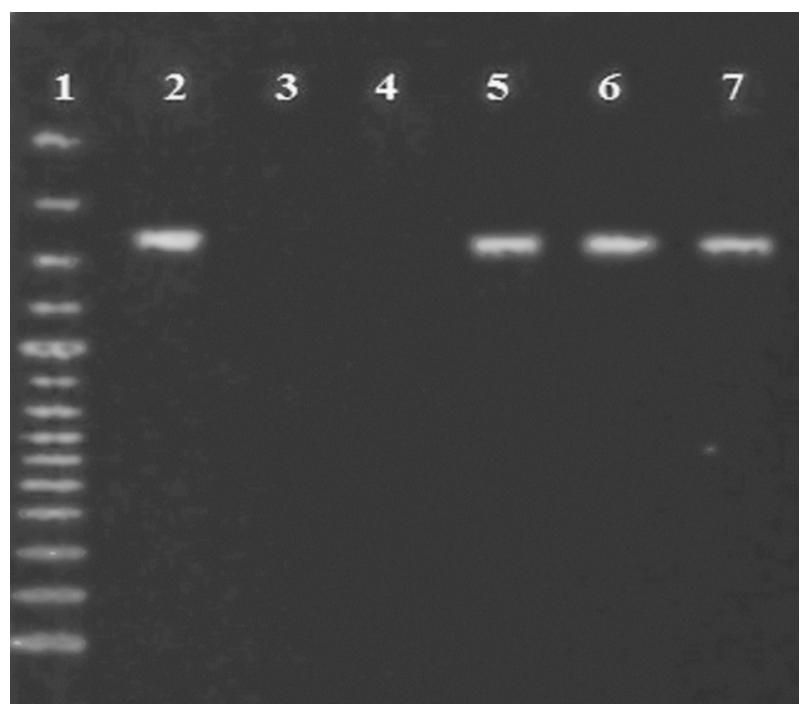

Fig. 1. PCR amplification of a partial sequence of CAV-2 E1B 19K gene (product size: $235 \mathrm{bp}$ ) from Polish dog. (1): molecular weight marker $=100 \mathrm{bp}$; (2) positive control (CAV DNA from vaccine Nobivac DHP-Intervet); (3) negative control (DNA from the whole blood of healthy dog); (4) negative results of PCR; $(5,6,7)$ positive results of PCR.

\section{Sequence analysis}

All 16 PCR products were sequenced. Due to development of the sequences in Lasergene DNA Star it was possible to create a phylogenetic tree showing the similarity between particular CAV-2 viruses and the sequence of the E1B $19 \mathrm{~K}$ gene fragment of the virus from the NCBI GenBank: AC 000003 (Fig. 2).

Analysis of the dendrogram made it possible to identify 3 polymorphs among the studied viral sequences. Eleven CAV-2 sequences (from viral isolates 001, 002, 003, 004, 007, 008, 009, 011, 012, 013, 016) were classified as type 1 polymorphs. Type 2 polymorphs included CAV-2 isolates 005, 006, 010, 014 and 015 , whereas type 3 polymorphs were represented by sequence $\mathrm{AC} 000003$. The homology between the studied sequences of own viral isolates was high, as evidenced by the small differences in the branch length of the phylogenetic tree, and ranged from 99.6 to $100 \%$. However, considerable differences were revealed between sequences of own isolates and the $\mathrm{AC}$ 000003 sequence of CAV-2 obtained from the online database, the homology being merely $78-78.4 \%$ (Fig. 3).

Analysis of individual amplicons in Lasergene DNA Star made it possible to assert that the most conserved sequence was observed in type 1 polymorphs, which exhibited $100 \%$ homology of nucleotide sequence:

TCAGTAAAAGGAGCAACAGTAAAGCCCC TGCGCAAAAGACCCCAAAAAGCGTGGTTTTC AGGTAAAATTTGCCAAAACCTGCCTTCCTCC TGTACCACTATATTGCCCACCACATCAGCCA AGGCAGGAAAACACCACCACCTAAAAAATC CAGGCGACAAAGTACTTCCCCTAATTATAGC TCTAAAAGTAAGGTAGTTTTCACAAATCTTAAGAGGGTCCATACTACCTG.

Sequences of the remaining isolates obtained in own studies were compared to this representative polymorph (Table 1). In sequences of the E1B 19K gene fragment of all the viruses classified as type 2 polymorphs, A-to-C nucleotide replacement was observed at position 45 when compared to the sequence of type 1 polymorphs. On the other hand, the AC 000003 sequence representing type 3 polymorphs differed from the sequence of type 1 polymorph isolates by as many as 44 nucleotide substitutions, and A-to-C nucleotide replacement at position 45 was observed, as in type 2 polymorphs. 


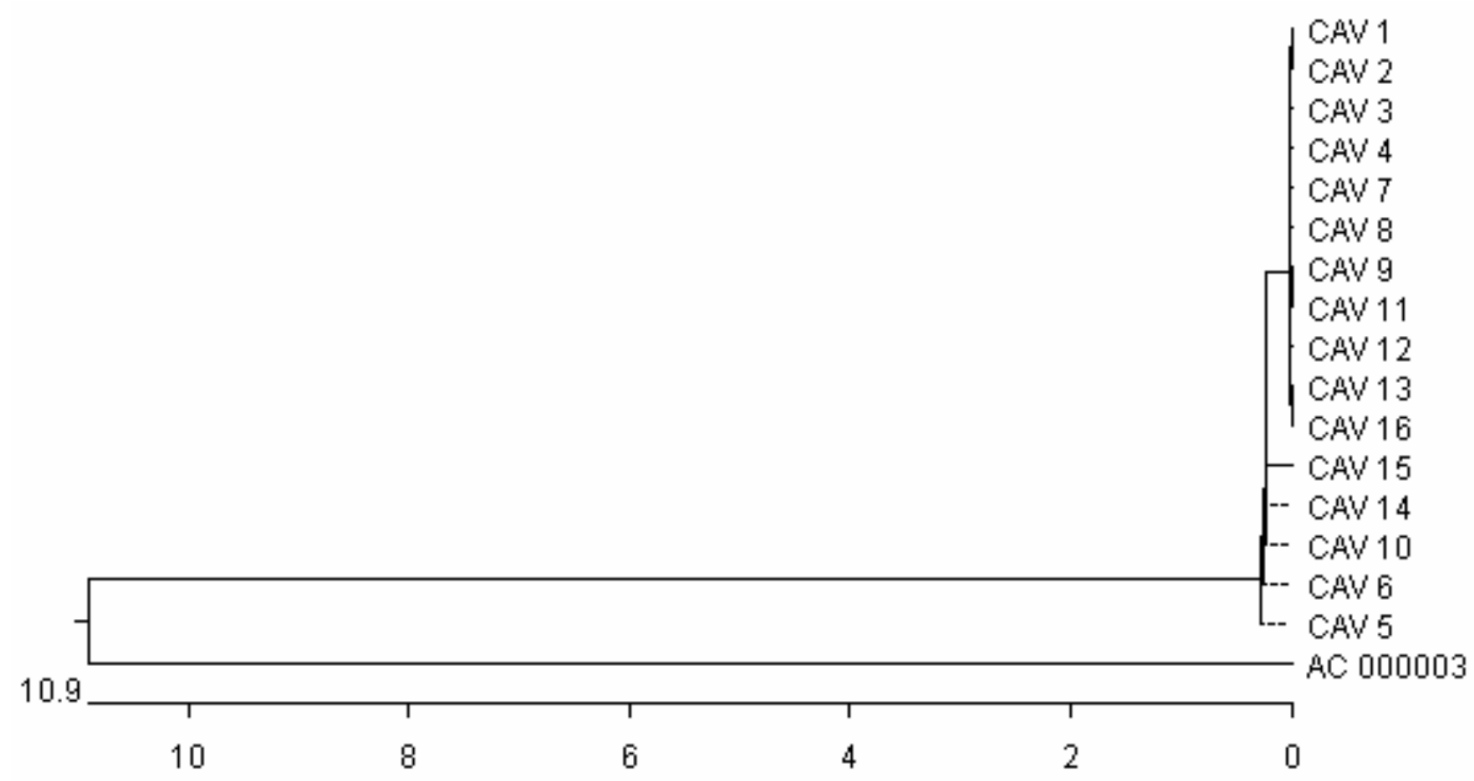

Fig. 2. Phylogenetic relationships between partial sequence of E1B-19K CAV-2 gene of isolates identified in our study and sequence AC 000003 deposited in GenBank.

\begin{tabular}{|c|c|c|c|c|c|}
\hline \multicolumn{6}{|c|}{ Ider } \\
\hline \multirow{5}{*}{ 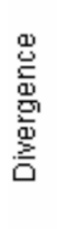 } & & 1 & 2 & 3 & \\
\hline & 1 & & 99.6 & 78.0 & 1 \\
\hline & 2 & 0.4 & & 78.4 & 2 \\
\hline & 3 & 22.0 & 21.5 & & 3 \\
\hline & & 1 & 2 & 3 & \\
\hline
\end{tabular}

polymorphic type 1 polymorphic type 2 AC 000003

Fig. 3. Percent identity of a partial sequence of E1B-19K CAV-2 gene from own study (polymorphic types 1 and 2) and sequence AC 000003 deposited in GenBank.

Translation of the studied nucleotide sequences using the software made it possible to show amino acid changes in particular CAV-2 viruses. The reference point was the amino acid sequence of type 1 polymorphs:

S V K GAT V KP LR KR PQKA WFS GKICQNLPSSCTTILPTTSAKAGKHHHLKNPGDKV LPLIIALKVR-FSQILRGSILPV.

Comparison of amino acid sequences of type 2 polymorphs with type 1 polymorphs showed, as with the analysis of nucleotide sequences, the presence of one constant Q-to-H substitution at position 15.

In contrast, the amino acid sequence of a fragment of the E1B 19K gene placed in the NCBI GenBank at no. AC 000003 differed from an analogical sequence of type 1 polymorphs by 19 substitutions. In that case all the observed mutations were located at the section between amino acid 10-65 (Table 2).

\section{Discussion}

The early region E1 of the CAV-2 genome is responsible for regulating viral gene expression during cell infection. E1 has two separate transcription units marked as E1A and E1B, E1B being responsible for expression of proteins E1B-19K and E1B-55K (White et al. 1988). By suppressing expression of cell proteins Bax, Bak and Nbk/Bik (Rao et al. 1999), the E1B-19K gene inhibits the E1A-induced apoptosis of the host cell. E1B is a marker frequently used in diagnostics of adenoviral infections (Flaschker et al. 2007, Cardoso et al. 2008, Spurgeon and Ornelles 2009, Schreiner et al. 2011). The gene is widely considered to be characterised by a stable nucleotide sequence and, similarly to the CAV-2 virus, it does not exhibit mutation tendencies. This view may be confirmed by the results of studies of Benetka et al. (2006) who analysed the CAV-2 genome isolated from the lungs and brain of dead pups from Austria with dyspnoea symptoms and neurological disorders. All the isolates of the adenovirus obtained by the authors showed $99.8 \%$ homology of the nucleotide sequence with the standard strain of CAV-2 - Toronto A26/61.

However, a more detailed analysis of the CAV-2 genome seems to contradict this view. This may be confirmed by results of English studies (Macartney et al. 1988). The monitoring of the presence of CAV-2 in the faeces of dogs carried out in the UK made it possible to reveal this virus in almost $41 \%$ of specimens exhibiting diarrhoea symptoms. After amplification 
Table 1. Positions of changes in nucleotide sequences of CAV-2 E1B 19K gene, in virus isolates obtained in own study (polymorphic types 1 and 2) and AC 000003 sequence deposited in GenBank.

\begin{tabular}{|c|c|c|}
\hline $\begin{array}{c}\text { CAV-2 } \\
\text { polymorphic } \\
\text { types }\end{array}$ & Changes & Position \\
\hline Type 1 & None & - \\
\hline Type 2 & $\mathrm{~A} \rightarrow \mathrm{C}$ & 45 \\
\hline \multirow[t]{37}{*}{ AC 000003} & $\mathrm{~A} \rightarrow \mathrm{G}$ & 18,21 \\
\hline & $\mathrm{C} \rightarrow \mathrm{T}$ & 27 \\
\hline & $\mathrm{T} \rightarrow \mathrm{C}$ & 29 \\
\hline & $\mathrm{G} \rightarrow \mathrm{T}$ & 30 \\
\hline & $\mathrm{C} \rightarrow \mathrm{A}$ & 33 \\
\hline & $\mathrm{A} \rightarrow \mathrm{C}$ & 39 \\
\hline & $\mathrm{C} \rightarrow \mathrm{G}$ & 40 \\
\hline & $\mathrm{A} \rightarrow \mathrm{C}$ & 45 \\
\hline & $\mathrm{C} \rightarrow \mathrm{T}$ & 50 \\
\hline & $\mathrm{T} \rightarrow \mathrm{G}$ & 55 \\
\hline & $\mathrm{T} \rightarrow \mathrm{A}$ & 63 \\
\hline & $\mathrm{A} \rightarrow \mathrm{C}$ & 65 \\
\hline & $\mathrm{G} \rightarrow \mathrm{C}$ & 71 \\
\hline & $\mathrm{T} \rightarrow \mathrm{C}$ & 91 \\
\hline & $\mathrm{A} \rightarrow \mathrm{T}$ & 94 \\
\hline & $\mathrm{A} \rightarrow \mathrm{G}$ & 102 \\
\hline & $\mathrm{G} \rightarrow \mathrm{A}$ & 105 \\
\hline & $\mathrm{C} \rightarrow \mathrm{G}$ & 108 \\
\hline & $\mathrm{C} \rightarrow \mathrm{A}$ & 111 \\
\hline & $\mathrm{A} \rightarrow \mathrm{G}$ & 117 \\
\hline & $\mathrm{G} \rightarrow \mathrm{A}$ & 123 \\
\hline & $\mathrm{G} \rightarrow \mathrm{T}$ & 127 \\
\hline & $\mathrm{A} \rightarrow \mathrm{G}$ & $129,132,134,140$ \\
\hline & $\mathrm{A} \rightarrow \mathrm{C}$ & 147,149 \\
\hline & $\mathrm{T} \rightarrow \mathrm{G}$ & 150 \\
\hline & $\mathrm{A} \rightarrow \mathrm{T}$ & 153 \\
\hline & $\mathrm{C} \rightarrow \mathrm{A}$ & 159 \\
\hline & $\mathrm{A} \rightarrow \mathrm{G}$ & 165 \\
\hline & $\mathrm{T} \rightarrow \mathrm{A}$ & 168 \\
\hline & $\mathrm{C} \rightarrow \mathrm{T}$ & 171,172 \\
\hline & $\mathrm{A} \rightarrow \mathrm{G}$ & 174 \\
\hline & $\mathrm{C} \rightarrow \mathrm{A}$ & 182 \\
\hline & $\mathrm{T} \rightarrow \mathrm{C}$ & 183 \\
\hline & $\mathrm{A} \rightarrow \mathrm{G}$ & 186 \\
\hline & $\mathrm{A} \rightarrow \mathrm{C}$ & 192 \\
\hline & $\mathrm{G} \rightarrow \mathrm{A}$ & 194, 195 \\
\hline & $\mathrm{A} \rightarrow \mathrm{G}$ & 207 \\
\hline
\end{tabular}

the obtained viral DNA was subjected to digestion by restriction enzymes Bam H1 and Pst 1. Electrophoresis in the agarose gel showed identical restriction patterns for all the English isolates. One isolate, marked as 9228, was chosen as the standard isolate and it was compared to the strains of type 2 canine adenovirus available in the gene bank, used to produce vaccines against canine adenovirosis. Analysis of sequences of the viruses showed they were entirely different, which suggested the need for continuous genetic monitoring of CAV-2 and for update of immunopreparations against this disease.
Table 2. Positions of changes in amino acid sequences of CAV-2 E1B 19K gene, in virus isolates obtained in own study (polymorphic types 1 and 2) and AC 000003 sequence deposited in GenBank.

\begin{tabular}{ccc}
\hline $\begin{array}{c}\text { CAV-2 } \\
\text { polymorphic } \\
\text { types }\end{array}$ & Changes & Position \\
\hline Type 1 & None & - \\
\hline Type 2 & $\mathrm{Q} \rightarrow \mathrm{H}$ & 15 \\
\hline AC 000003 & $\mathrm{L} \rightarrow \mathrm{P}$ & 10 \\
& $\mathrm{R} \rightarrow \mathrm{S}$ & 13 \\
& $\mathrm{P} \rightarrow \mathrm{A}$ & 14 \\
& $\mathrm{Q} \rightarrow \mathrm{H}$ & 15 \\
& $\mathrm{~A} \rightarrow \mathrm{V}$ & 17 \\
& $\mathrm{~F} \rightarrow \mathrm{V}$ & 19 \\
$\mathrm{~K} \rightarrow \mathrm{T}$ & 21 \\
& $\mathrm{C} \rightarrow \mathrm{S}$ & 23 \\
& $\mathrm{C} \rightarrow \mathrm{R}$ & 31 \\
& $\mathrm{~T} \rightarrow \mathrm{S}$ & 32 \\
& $\mathrm{I} \rightarrow \mathrm{M}$ & 34 \\
& $\mathrm{G} \rightarrow \mathrm{W}$ & 43 \\
& $\mathrm{H} \rightarrow \mathrm{R}$ & 45 \\
& $\mathrm{H} \rightarrow \mathrm{R}$ & 37 \\
$\mathrm{~K} \rightarrow \mathrm{N}$ & 49 \\
$\mathrm{~N} \rightarrow \mathrm{T}$ & 50 \\
& $\mathrm{D} \rightarrow \mathrm{E}$ & 53 \\
& $\mathrm{~A} \rightarrow \mathrm{D}$ & 61 \\
$\mathrm{R} \rightarrow \mathrm{K}$ & 65 \\
\hline & &
\end{tabular}

Harasawa et al. (1994) studied polymorphism of the E1 gene of type 2 adenoviruses isolated from dogs. The authors amplified the E1 region of the CAV-2 genome using PCR, and then they subjected the amplification products to a restriction analysis using Hae III and Rsa I enzymes. Based on the E1 restriction patterns obtained they demonstrated two polymorphs of CAV-2, which occurred only in Japan. Results of Harasawa et al. (1994) coincide with our own observations and they may suggest the static presence of endemic CAV-2 strains in certain geographic areas.

Our own studies included a molecular analysis of a fragment of the E1B gene from sixteen CAV-2 strains isolated from dogs from the Lublin area with clinical symptoms of kennel cough. The analysis of sequences of the E1B gene of own isolates led to identification, as in the paper of Harasawa et al. (1994), of 2 polymorphs, differing only by one substitution at position 45 of the studied gene section. This was the basis for determining the similarity of the E1B gene between native isolates as high, ranging from 96 to $100 \%$. In contrast, a comparison of sequences of our own isolates with the standard sequence AC 000003 of the studied gene obtained from the GenBank (currently this is the only available sequence of the CAV-2 E1B gene), showed a similarity of 
$78-78.4 \%$, with differences pertaining to as many as 44 substitutions. This shows a low homology of Polish isolates to the standard isolate from the GenBank.

The alterations within the E1B gene may confirm the development of new types of CAV-2, which has great epizootic and taxonomic relevance. This was also why we analysed this gene in our study. No molecular monitoring of CAV-2 isolated from clinical cases of kennel cough in dogs has been carried out in Poland so far; our studies are pilot studies. An almost $100 \%$ similarity between the studied isolates shows that the diagnosed cases of adenovirus infections in dogs were caused by a genetically stable CAV-2 virus. However, it differed considerably from standard isolates. The results obtained may suggest the static presence of a CAV-2 strain, characterised by a specific nucleotide sequence of the E1 gene and differing from the vaccine strains of the adenovirus, in the Lublin area. This could explain the inefficacy of the vaccines administered to the study dogs. For the issue of CAV-2 variability to be considered more broadly, a more detailed molecular analysis of the virus is necessary to examine other genes in addition to E1 and determine the similarity of our own isolates to more than one standard strain of the pathogen.

\section{References}

Appel M, Binn LN (1987) Canine infectious tracheobronchitis. Short review: kennel cough. In: Appel MJ (ed) Virus infections of carnivores. Elsevier Science Publisher, Amsterdam, pp 201-211.

Appel MJG, Pickerill RH, Menegus M, Percy DH, Parsonson IM, Sheffy BE (1970) Current status of canine respiratory disease. Procedings of the 20th Gaines Veterinary Symposium, Manhattan, USA, pp 15-23.

Benetka V, Weissenbock H, Kudielka I, Pallan C, Rothmuller G, Mostl K (2006) Canine adenovirus type 2 infection in four puppies with neurological signs. Vet Rec 158: 91-94.

Buonavoglia C, Martella V (2007) Canine respiratory viruses. Vet Res 38: 355-373.

Cardoso FM, Kato SE, Huang W, Flint SJ, Gonzalez RA (2008) An early function of the adenoviral E1B $55 \mathrm{kDa}$ protein is required for the nuclear relocalization of the cellular p53 protein in adenovirus-infected normal human cells. Virology 378: 339-346.

Chaturvedi U, Tiwari AK, Ratta B, Ravindra PV, Rajawat YS, Palia SK, Rai A (2008) Detection of canine adenoviral infections in urine and faeces by the polymerase chain reaction. J Virol Methods 149: 260-263.

Davison AJ, Benko M, Harrach B (2003) Genetic content and evolution of adenoviruses. J Gen Virol 84: 2895-2908.

Ditchfield J, Macpherson LW, Zbitnew A (1962) Association of a canine adenovirus (Toronto A 26/61) with an outbreak of laryngotracheitis ("kennel cough"). A preliminary report. Can Vet J 3: 238-247.

Fairchild GA, Cohen D (1969) Serologic study of a canine adenovirus (Toronto A26/61) infection in dogs. Am J Vet
Res 30: 923-928.

Flaschker N, Feyen O, Fend S, Simon E, Schadewaldt P, Wendel U (2007) Description of the mutations in 15 subjects with variant forms of maple syrup urine disease. J Inherit Metab Dis 30: 903-909.

Gerhold RW, Allison AB, Temple DL, Chamberlain MJ, Strait KR, Keel MK (2007) Infectious canine hepatitis in a gray fox (Urocyon cinereoargenteus). J Wildl Dis 43: 734-736.

Hamelin C, Jouvenne P, Assaf R (1985) Association of a type-2 canine adenovirus with an outbreak of diarrhoeal disease among a large dog congregation. J Diarrhoeal Dis Res 3: 84-87.

Hamelin C, Marsolais G, Assaf R (1984) Interspecific differences between the DNA restriction profiles of canine adenoviruses. Experientia 40: 482.

Harasawa R, Tohya Y, Yoshida M, Kataoka Y, Katae $\mathrm{H}$ (1994) Two genomic variations in the E1 region of canine adenovirus type 2 strains. Vet Microbiol 40: 373-378.

Koncicki A, Krasnodębska-Depta A, Mazur-Gonkowska B (2006) New data concerning the significance of adenovirus in poultry pathogenicity. Med Weter 62: 739-743.

Lynch JP 3rd, Fishbein M, Echavarria M (2011) Adenovirus. Semin Respir Crit Care Med 32: 494-511.

Macartney L, Cavanagh HM, Spibey N (1988) Isolation of canine adenovirus- 2 from the faeces of dogs with enteric disease and its unambiguous typing by restriction endonuclease mapping. Res Vet Sci 44: 9-14.

Marusyk RG (1972) Comparison of the immunological properties of two canine adenoviruses. Can J Microbiol 18: 817-823.

Marusyk RG, Norrby E, Lundqvist U (1970) Biophysical comparison of two canine adenoviruses. J Virol 5: 507-512.

Morrison MD, Onions DE, Nicolson L (1997) Complete DNA sequence of canine adenovirus type 1 . J Gen Virol 78: 873-878.

Rao L, Modha D, White E (1997) The E1B 19K protein associates with lamins in vivo and its proper localization is required for inhibition of apoptosis. Oncogene 15: $1587-1597$.

Schreiner S, Wimmer P, Groitl P, Chen SY, Blanchette P, Branton PE, Dobner T (2011) Adenovirus type 5 early region 1B 55K oncoprotein-dependent degradation of cellular factor Daxx is required for efficient transformation of primary rodent cells. J Virol 85: 8752-8765.

Spurgeon ME, Ornelles DA (2009) The adenovirus E1B 55-kilodalton and E4 open reading frame 6 proteins limit phosphorylation of eIF2alpha during the late phase of infection. J Virol 83: 9970-9982.

Swango LJ, Eddy GA, Binn LN (1969) Serologic comparisons of infectious canine hepatitis and Toronto A26/61 canine adenoviruses. Am J Vet Res 30: 1381-1387.

Truszczyński M, Pejsak Z (2012) Diarrheal diseases in pigs caused by facultatively pathogenic viruses. Med Weter 68: 9-14.

White E, Denton A, Stillman B (1988) Role of the adenovirus E1B 19,000-dalton tumor antigen in regulating early gene expression. J Virol 62: 3445-3454.

Wieliczko A, Tomanek B, Kuczkowski M (2003) Prevalence of infectious diseases in ring-necked pheasant flocks in Poland. Pol J Vet Sci 6: 177-182.

Wiśniewski E (2004) Adenoviral infections in horse. Med Weter 60: 1139-1142.

Yamamoto R, Marusyk RG (1968) Morphological studies of a canine adenovirus. J Gen Virol 2: 191-194. 